www.jmscr.igmpublication.org

Impact Factor 5.84

Index Copernicus Value: 71.58

ISSN (e)-2347-176x ISSN (p) 2455-0450

crossref DOI: _https://dx.doi.org/10.18535/jmscr/v5i11.149

Journal Of Medical Science And Clinical Research

IGM Publication

An Official Publication of IGM Publication

\title{
A Study on the Clinical Profile of Late Onset Asthma in Females in a Tertiary Care Centre in South Kerala
}

\author{
Authors \\ Dr Renymol B ${ }^{1}$, Dr Ambili $\mathbf{N R}^{2}$ \\ ${ }^{1}$ Associate Professor, Department of Medicine, Government TD Medical College, Alappuzha \\ ${ }^{2}$ Assisstant Professor, Department Of Medicine, Government TD Medical College, Alappuzha \\ Correspondence Author \\ Dr Ambili NR \\ Assistant Professor, Dept of Medicine, Govt TD Medical College, Vandanam PO, Alappuzha 688005 \\ Email:drambilinr@gmail.com, Mobile no: 9447248174
}

\begin{abstract}
Introduction: Asthma is a chronic inflammatory disorder of the airways. Adult onset asthma generally refers to the onset of asthma for the first time in some one of middle age or older. It is more common in females. It is postulated to be due to the effect of sex hormones in women. Studies have shown that women with adult onset asthma have increased risk of coronary heart disease and stroke. The aim of the study was to study the clinical profile and pulmonary function abnormalities in these patients, find out the aetiological factors for adult onset asthma in these patients and to know whether late onset asthma has any relation with coir industry which is a common industry in this area.
\end{abstract}

Materials and Methods: Fifty female patients presenting with episodic wheezing with the onset of symptoms after the age of 40 years were included in the study. A detailed history, physical examination, blood investigations including the absolute eosinophil count, chest radiography and pulmonary function tests were done in them. Skin tests were done only in those patients with history of allergy.

Observations: In our study majority of the patients were in the age group 40-49 and 50-59 years. Age of onset of symptoms was below 50 years for $46 \%$ of patients. $82 \%$ patients were living in costal ares.30 patients (60\%) reported history of allergic rhinitis. Of the total 30 patients with allergic rhinitis, $46 \%$ had onset of asthma symptoms before 50 years of age and 80\% of patients had asthma symptoms before 60 years. FEV1 values were analyzed in relation with age of patient and duration of symptoms and no correlation was found. FEVI reversibility was less in coir workers compared to housewives. Patients in the older age group had lower PEF 25-75 values compared to those in the younger age group. Allergy testing was done in 10 patients, of this 4 patients were found to be sensitive to various allergens like house dust, wheat dust etc. All these 4 patients had allergic rhinitis.

Conclusions: Allergic symptoms are common in these patients and atopy may be a reason for development adult onset asthma. In women exposure to kitchen smoke could be an etiological factor for development of asthma. Adult onset asthma was found to be more common in workers in coir industry. FEVI reversibility was less in coir workers compared to other occupational groups. Small air way dysfunction was more common in older age group patients with late onset asthma.

Keywords: Late onset asthma. 


\section{Introduction}

Asthma is a chronic inflammatory disorder of the airways .The chronic inflammation is associated with airway hyper responsiveness leading to recurrent episodes of wheezing, breathlessness, chest tightness and cough. The prevalence of asthma is increasing. The trigger factors for asthma include indoor and outdoor allergens, microbes, diet, tobacco smoke, air pollution etc. According to etiology, asthma may be classified as extrinsic or intrinsic. Extrinsic asthma is asthma that occurs in atopic individuals i.e., people with an increased amount of immunoglobulin $\mathrm{E}$ antibodies against common environmental allergens. Asthma induced by unknown causes in non-atopic individuals is defined as intrinsic asthma. Adult onset asthma generally refers to the onset of asthma for the first time in some one of middle age or older ${ }^{[1]}$. It is more common in females. It is postulated to be due to the effect of sex hormones in women ${ }^{[2]}$. Studies have shown that women with adult onset asthma have increased risk of coronary heart disease and stroke [3]. The usual symptoms of asthma are generally present with varying degrees of breathlessness, wheeze and cough in adult onset asthma also. It is generally believed that true allergic asthma starts very seldom in old age and atopy is less common in those with late onset asthma ${ }^{[4]}$. The role of air pollution ${ }^{[5]}$, tobacco smoke $\mathrm{e}^{[6]}$, vapor $\mathrm{dust}^{[7]}$, smoke, respiratory infections ${ }^{[8]}$, obesity ${ }^{[9]}$, rhinitis and occupational exposures ${ }^{[10]}$ in the development of adult onset asthma is well documented. The differential diagnosis for chronic dyspnoea and cough is broad in elderly and includes COPD, congestive cardiac failure, bronchiectasis, obesity, lung cancer etc. It is important to make a correct diagnosis in this situation as the treatment of these conditions varies. Demonstration of reversible airway obstruction in pulmonary function testings help in arriving at a correct diagnosis. Studies have postulated the role of various allergens, infections, and tobacco smoke, and rhinitis, medications like beta blockers, foods, and allergens at work place in the development of adult onset asthma. Dust, smoke etc can precipitate adult onset asthma and can lead to exacerbation of asthma. This is particularly significant in women exposed to domestic smoke. Occupational asthma may account for a significant proportion of adult onset asthma. Kerala is an important producer of coir -a natural fiber obtained from coconut. Coconut husk is immersed in water for many months and then it is beaten and fbres are removed and the fibers are spun to make coir. This is mainly done as a cottage industry and women are mainly employed in this. Coir is processed in factories to make different coir products. The women in this work are exposed to dust and dampness and respiratory diseases are common in them.

\section{Materials and Methods}

This study was conducted at a tertiary care centre in South Kerala. 50 women with symptoms of adult onset asthma were included in the study. The aim of the study was to study the clinical profile and pulmonary function abnormalities in these patients, find out the aetiological factors for adult onset asthma in these patients and to know whether late onset asthma has any relation with coir industry which is a common industry in this area. Fifty female patients presenting with episodic wheezing with the onset of symptoms after the age of 40 years were included in the study. Patients with history of any significant respiratory disease before the age of 40 years were excluded. Patients with any abnormality in the chest $\mathrm{x}$-ray were also excluded. Written informed consent was obtained from all the patients. A detailed history including age of onset of symptoms, duration of symptoms, allergy history, occupation, family history of allergy etc was taken. A detailed clinical examination, blood examination including absolute eosinophil count, chest $\mathrm{x}$-ray and pulmonary function testing were done for all patients. Kit Micro computerized pulmonary function apparatus was used. PFT was done in the morning between 9am and 11am. Patients were asked to skip their morning dose of 


\section{JMSCR Vol||05||Issue||11||Page 30688-30695||November}

oral and inhaled bronchodilators on the day of testing. While doing spirometry test was repeated three times and the best value was taken as the test value. After this patients were nebulised using 1 $\mathrm{ml}$ salbutamol nebulizer solution diluted in $3 \mathrm{ml}$ normal saline for 10 minutes. Spirometry was repeated after 10 minutes and FEV1 reversibility was assessed. Allergy testing was done for 10 patients with allergy history. These patients were asked to stop antihistamines 2 weeks prior to allergy testing. Aqueous extract of purified allergens were obtained from Bioproducts and Diagnostics Pvt Ltd. The allergens included ants, mosquito, cockroach, housefly, aspergillus flavus, aspergillus fumigates, aspergillus niger, aspergillus tamari, aspergillus versicolor, cotton dust, house dust, wheat dust, candida albicans and mucor. A control using normal saline was also included. $0.2 \mathrm{ml}$ of purified allergen extracts were injected intradermally using $26 \mathrm{~g}$ needle on the volar aspect of forearm. Results were read after 20 minutes. An induration of more than 3 times control was taken as a positive test.

\section{Observations}

Total 50 patients were included in the study.

Figure 1: Age distribution of patients

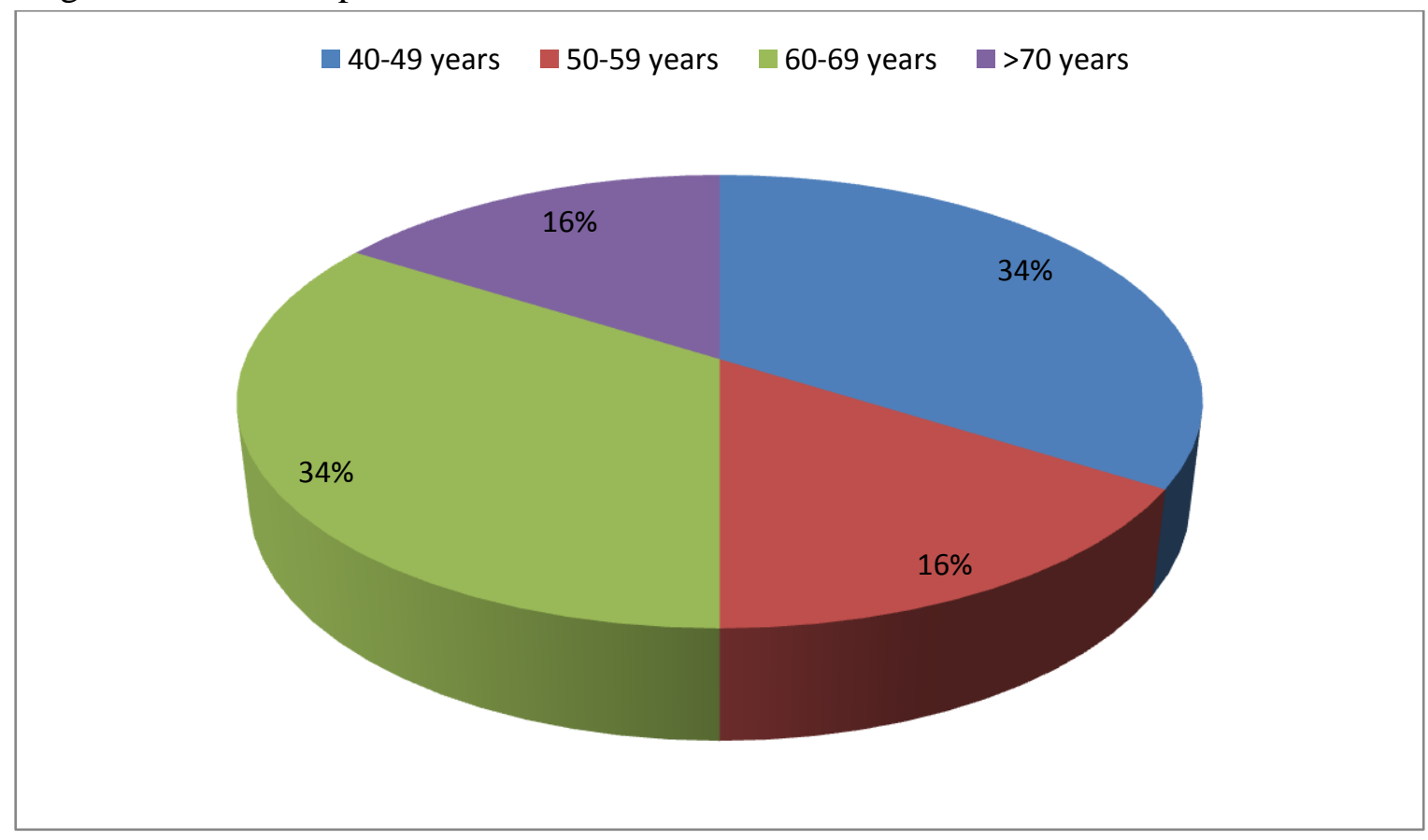

Table 1: Age of onset of symptoms:

\begin{tabular}{|l|c|c|}
\hline Age group & Number & Percentage \\
\hline 40-49 years & 23 & 46 \\
50-59 years & 16 & 32 \\
60-69 years & 9 & 18 \\
>70 years & 2 & 4 \\
\hline TOTAL & & 50 \\
\hline
\end{tabular}


Figure 2: Duration of symptoms:

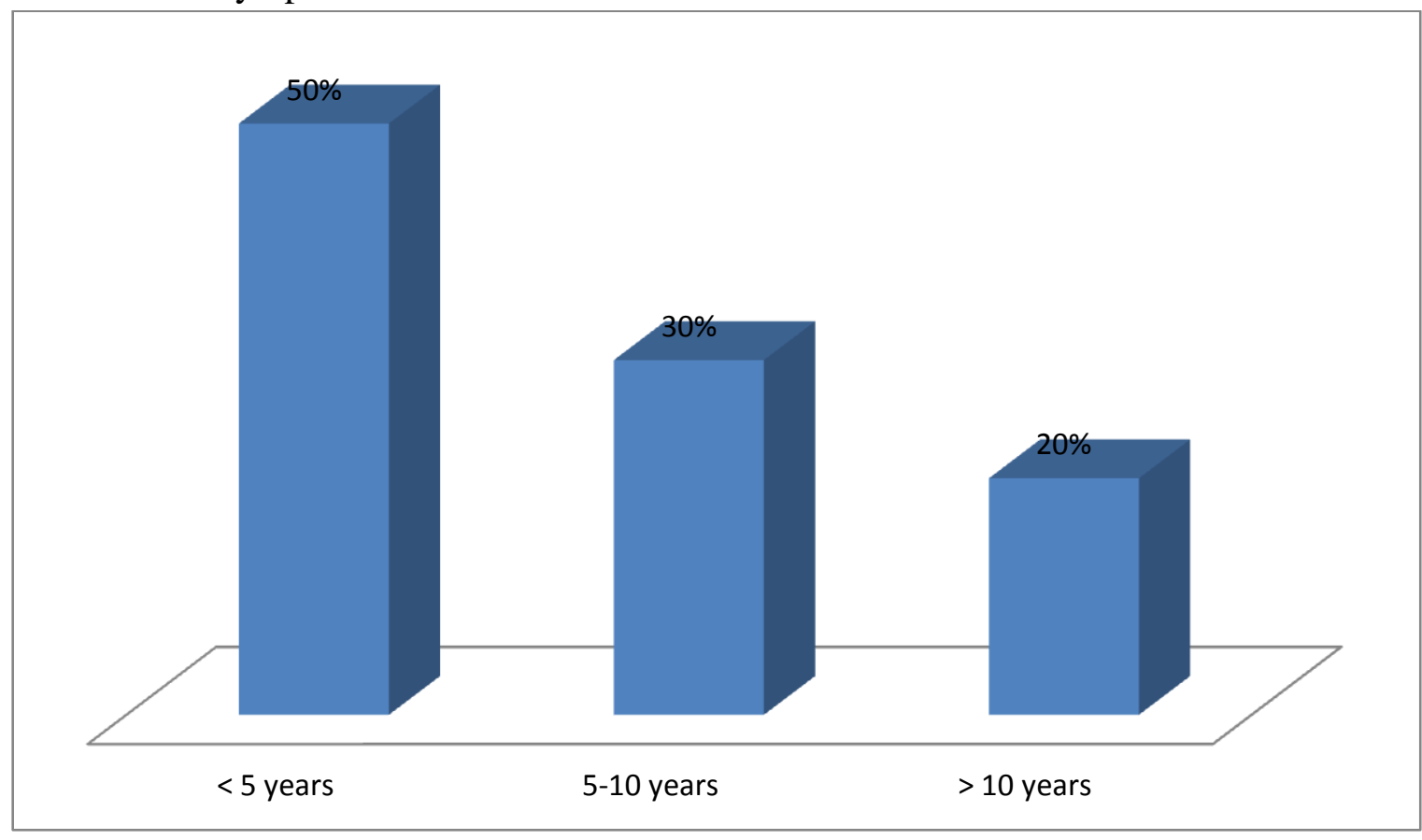

Table 2: Proximity to factory:

\begin{tabular}{|l|c|c|}
\hline Proximity to factory & Number & Percentage \\
\hline Coir factory & 8 & 16 \\
Spinning mill & 2 & 4 \\
Flour mill & 1 & 2 \\
\hline
\end{tabular}

Figure 3: Occupation of patients

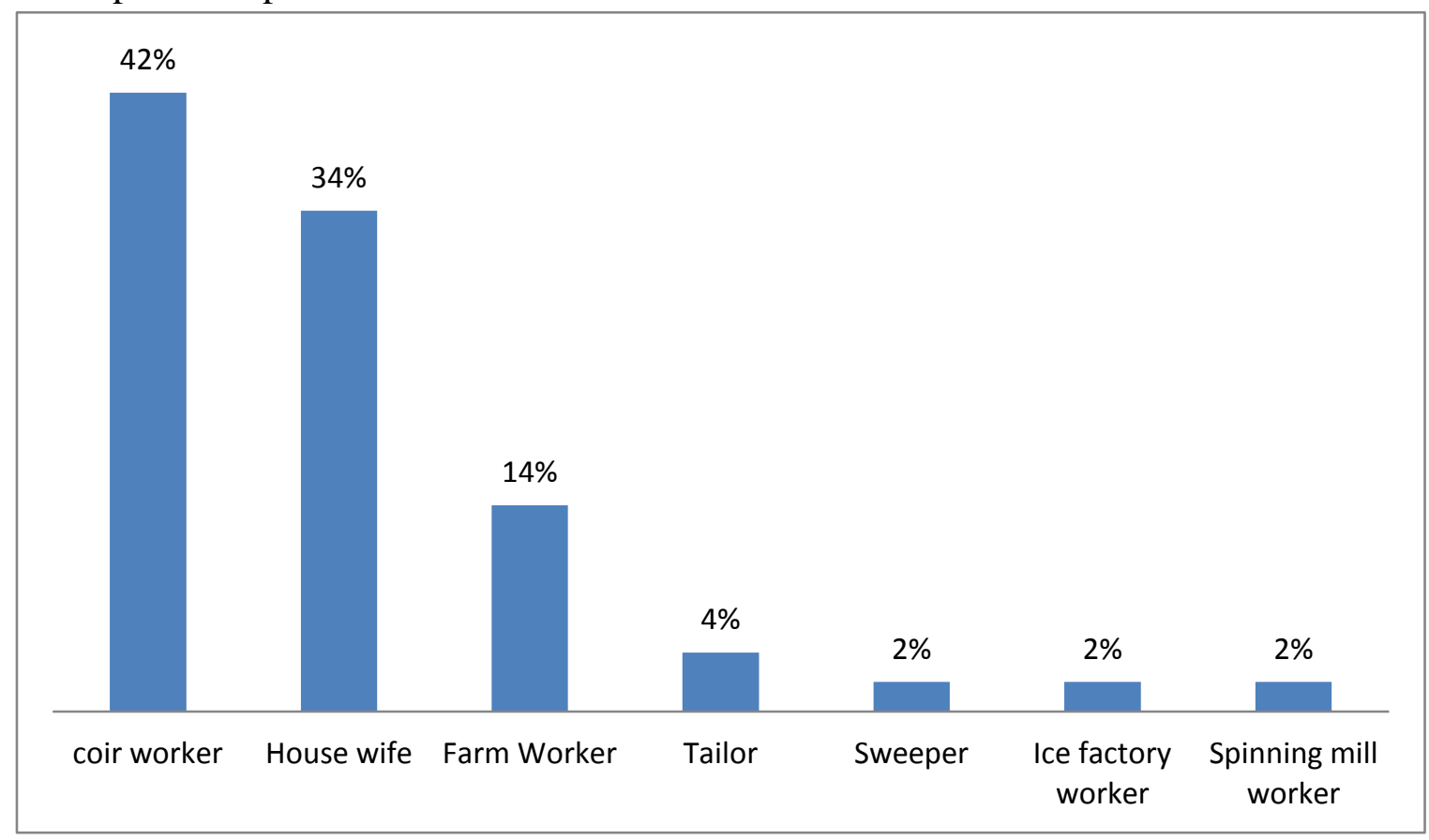


Table 3: Presence of other allergic disease

\begin{tabular}{|l|c|c|}
\hline Other allergic disease & Number & Percentage \\
\hline Allergic Rhinitis & 30 & $60 \%$ \\
Allergic conjunctivitis & 15 & $30 \%$ \\
Rhinitis and conjunctivitis & 13 & $26 \%$ \\
\hline
\end{tabular}

Table 4: Presenting symtoms:

\begin{tabular}{|l|c|c|}
\hline Symptoms & Number & Percentage \\
\hline Wheezing & 3 & $6 \%$ \\
Wheezing and cough & 47 & $94 \%$ \\
\hline Total & 50 & $100 \%$ \\
\hline
\end{tabular}

Table 5: Type of fuel used for domestic cooking:

\begin{tabular}{|l|c|c|}
\hline Type of fuel & Number & Percentage \\
\hline Firewood & 50 & $100 \%$ \\
Firewood and gas & 10 & $20 \%$ \\
Firewood and kerosene & 4 & $8 \%$ \\
Firewood, gas and kerosene & 2 & $4 \%$ \\
\hline
\end{tabular}

Figure 4: Exposure to passive smoking

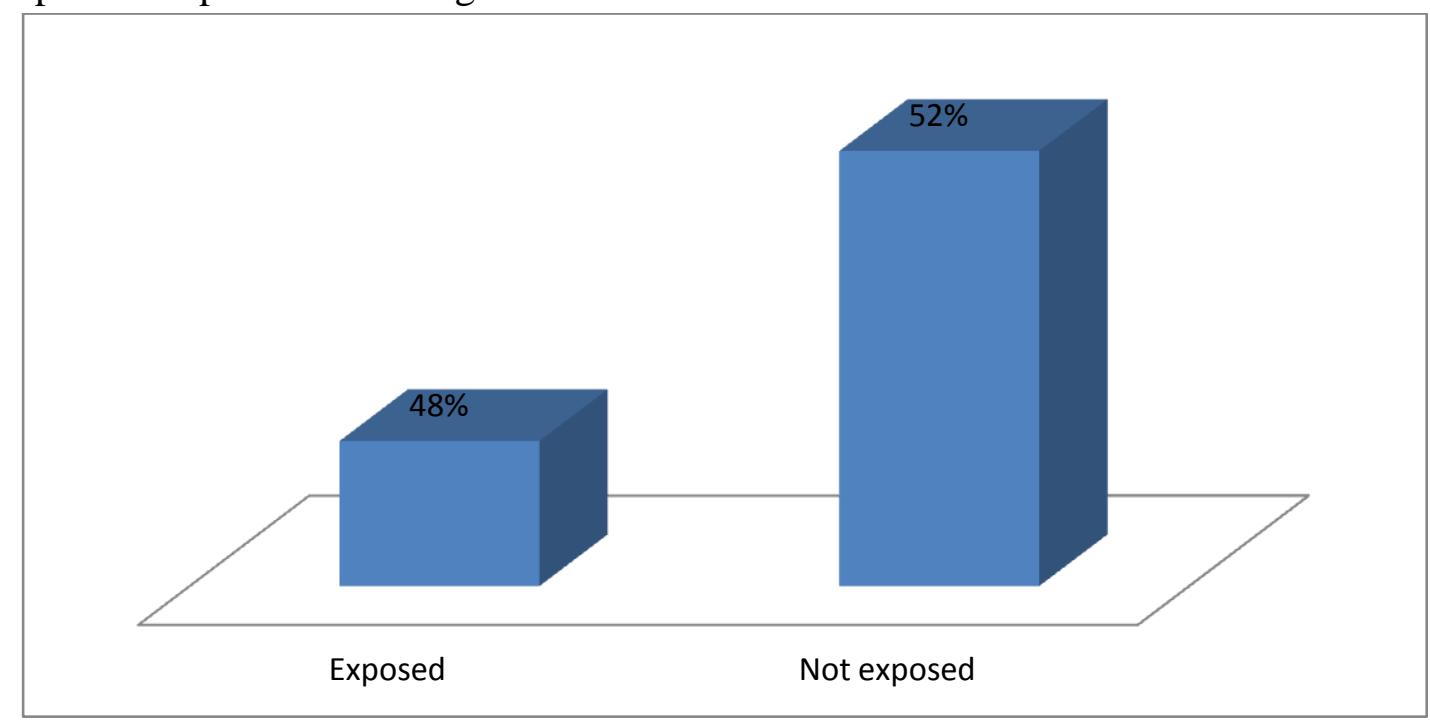

Table 6: Presence of Eosinophilia:

\begin{tabular}{|l|c|c|}
\hline Absolute Eosinophil Count & Number & Percentage \\
\hline$>500$ & 19 & $38 \%$ \\
$<500$ & 31 & $62 \%$ \\
\hline Total & 50 & 100 \\
\hline
\end{tabular}


Figure 5: FEV 1 and Age group:

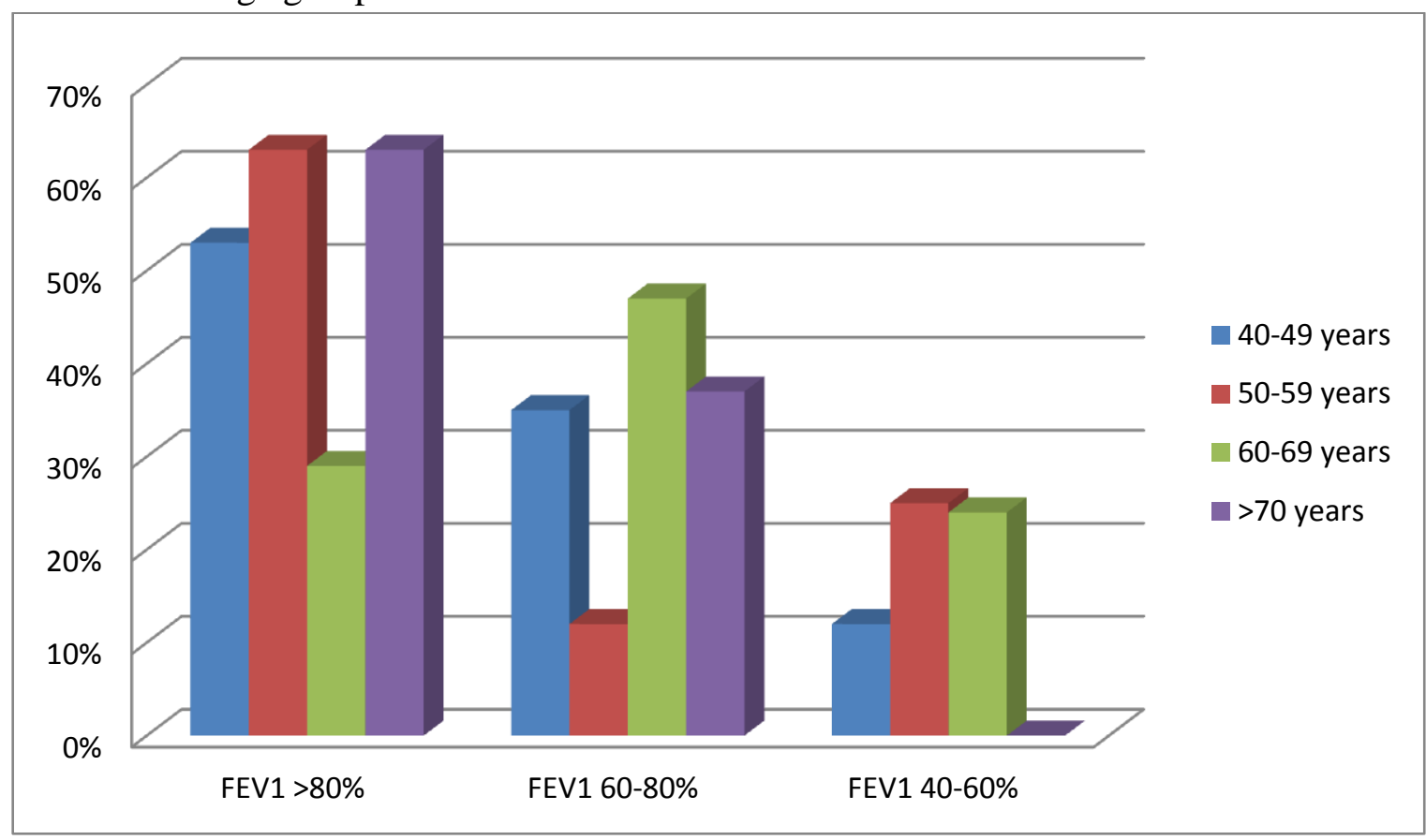

Figure 6: Age group and $\mathrm{PEF}$ 25-75

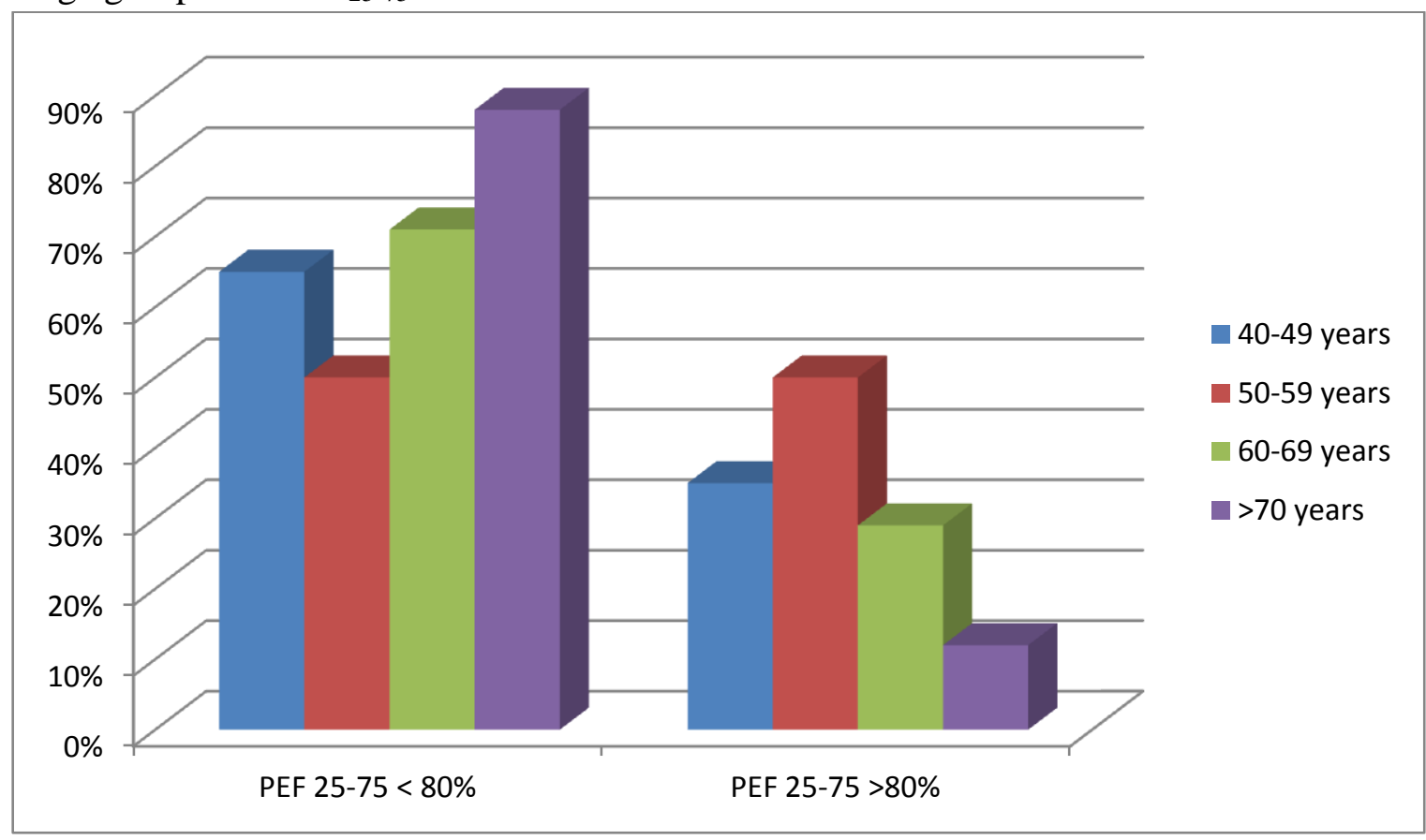

\section{Discussion}

In our study majority of the patients were in the age group 40-49 and 50-59 years. Age of onset of symptoms was below 50 years for $46 \%$ of patients. $82 \%$ patients were living in costal ares.30 patients $(60 \%)$ reported history of allergic rhinitis. Of the total 30 patients with allergic rhinitis, $46 \%$ had onset of asthma symptoms before 50 years of age and $80 \%$ of patients had asthma symptoms before 60 years. In a study by Ariano et al [11] reported that $72 \%$ of late onset asthma cases are allergic. Another study by Toren et $\mathrm{al}^{[12]}$ also reported association between allergic symptoms and late onset asthma. Many other studies have reported that adult onset asthma is non atopic ${ }^{[4]}$. Rhinitis itself can be a risk factor for development of late onset asthma ${ }^{[13]}$. Out of 21 coir workers, only 4 gave a family history of asthma indicating 
that majority of coir workers with late onset asthma were not atopic. Studies have postulated that allergic reaction to coir dust, fungi in moist dusty atmosphere or chemicals used in coir industry as the possible cause of respiratory symptoms in coir workers ${ }^{[14]}$. All the patients were exposed to kitchen smoke. Studies have shown increased risk of asthma in people exposed to smoke ${ }^{[5,6]}$. FEV1 values were analyzed in relation with age of patient and duration of symptoms and no correlation was found. FEV1 reversibility was less in coir workers compared to housewives. $18 \%$ of housewives had FEV1 reversibility more than $30 \%$, whereas only $10 \%$ of coir workers had FEV1 reversibility more than $30 \%$. PEF $25-75$ is a measure of small airway function. Patients in the older age group had lower PEF 25-75 values compared to those in the younger age group. $40 \%$ of patients below 60 years had PEF25-75 value more than $80 \%$, whereas only $20 \%$ of patients above 60 years had PEF25-75 value above $80 \%$ of predicted value. This indicates that small airway obstruction was more common in older age groups. Allergy testing was done in 10 patients, of this 4 patients were found to be sensitive to various allergens like house dust, wheat dust etc. All these 4 patients had allergic rhinitis.

\section{Conclusion}

Adult onset asthma is a common problem. Allergic symptoms are common in these patients and atopy may be a reason for development adult onset asthma. In women exposure to kitchen smoke could be an aetiological factor for development of asthma. Adult onset asthma was found to be more common in workers in coir industry. FEV1 reversibility was less in coir workers compared to other occupational groups. Small air way dysfunction was more common in older age group patients with late onset asthma.

\section{Limitations}

Sample size was not uniform in each age group. Allergy testing was not done in all the patients

\section{Acknowledgements}

We express our sincere gratitude to $\mathrm{Dr} C$ Ravindran, Professor, Department of Chest and TB for his invaluable help and guidance.

\section{References}

1. de Nijs SB, Venekamp LN, Bel EH. Adult-onset asthma: is it really different?. European Respiratory Review. 2013 Mar 1;22(127):44-52

2. Melgert BN, Ray A, Hylkema MN, Timens W, Postma DS. Are there reasons why adult asthma is more common in females?. Current allergy and asthma reports. 2007 Mar 1;7(2):143-50.

3. Onufrak SJ, Abramson JL, Austin HD, Holguin F, McClellan WM, Vaccarino LV. Relation of adult-onset asthma to coronary heart disease and stroke. The American journal of cardiology. 2008 May 1;101(9):1247-52

4. Amelink M, Nijs SB, Groot JC, Tilburg PM, Spiegel PI, Krouwels FH, Lutter R, Zwinderman AH, Weersink EJ, Brinke A, Sterk PJ. Three phenotypes of adult-onset asthma. Allergy. 2013 May 1;68(5):67480.

5. Gilmour MI, Jaakkola MS, London SJ, Nel AE, Rogers CA. How exposure to environmental tobacco smoke, outdoor air pollutants, and increased pollen burdens influences the incidence of asthma. Environmental health perspectives. 2006 Apr;114(4):627.

6. Öberg M, Jaakkola MS, Woodward A, Peruga A, Prüss-Ustün A. Worldwide burden of disease from exposure to second-hand smoke: a retrospective analysis of data from 192 countries. The Lancet. 2011 Jan 14;377(9760):139-46.

7. LeVan TD, Koh WP, Lee HP, Koh D, Yu $\mathrm{MC}$, London SJ. Vapor, dust, and smoke exposure in relation to adult-onset asthma and chronic respiratory symptoms: the Singapore Chinese Health Study. 
American journal of epidemiology. 2006 May 17;163(12):1118-28.

8. Johnston SL, Martin RJ. Chlamydophila pneumoniae and Mycoplasma pneumoniae: a role in asthma pathogenesis?. American journal of respiratory and critical care medicine. 2005 Nov 1;172(9):1078-89.

9. Leone N, Courbon D, Berr C, Barberger-Gateau P, Tzourio C, Alpérovitch A, Zureik M. Abdominal Obesity and Late-Onset Asthma: Cross-Sectional and Longitudinal Results: The 3C Study. Obesity. 2012 Mar 1;20(3):628-35.

10. Dykewicz MS. Occupational asthma: current concepts in pathogenesis, diagnosis, and management. Journal of Allergy and Clinical Immunology. 2009

11. Ariano R, Panzani RC, Augeri G. Late onset asthma clinical and immunological data: importance of allergy. Journal of investigational allergology \& clinical immunology. 1998;8(1):35-41.Mar 31;123(3):519-28.

12. Thorn J, Brisman J, Toren K. Adult-onset asthma is associated with self-reported mold or environmental tobacco smoke exposures in the home. Allergy. 2001 Apr 1;56(4):287-92.

13. Guerra S, Sherrill DL, Martinez FD, Barbee RA. Rhinitis as an independent risk factor for adult-onset asthma. Journal of Allergy and Clinical Immunology. 2002 Mar 31;109(3):419-25.

14. Panicker V, Karunakaran R, Ravindran C. Nasobronchial Allergy and Pulmonary Function Abnormalities Among Coir Workers of Alappuzha. JAPI. 2010 Jul;58:421. 